\title{
Na contramão da História: um estudo das estratégias de pesquisa psicológicas à luz da TAR ${ }^{1}$
}

\section{Out of way of History: a study concerning the rearch strattegies of psychology through ANT}

\section{En la contra ruta de la Historia: un estudio de las estrategias de investigación psicológicas a la luz de la TAR}

\section{Arthur Arruda Leal Ferreira*}

Universidade Federal do Rio de Janeiro - UFRJ, Rio de Janeiro, Rio de Janeiro, Brasil

\begin{abstract}
RESUMO
A meta deste trabalho é mapear as transformações nos experimentos psicológicos, apontando especialmente para os deslocamentos no lugar dos sujeitos participantes destes, notadamente no trânsito dos sujeitos treinados (onipresentes nos laboratórios psicológicos do século XIX) para os sujeitos ingênuos, que a partir da década de 1910, passam a se tornar o padrão, dentro de um tipo de design em que estes não tenham possibilidade de clareza do que está sendo experimentado. Esta transformação será discutida com base nos conceitos de docilidade e recalcitrância; se esta como possibilidade de resistência e colocação de novas questões por parte dos seres pesquisados já é considerada menor nas ciências humanas, a primeira, ou o assentimento perante as operações da pesquisa tenderia a se tornar maior nas operações com os sujeitos tratados como ingênuos.
\end{abstract}

Palavras-chave: experimentos psicológicos, sujeito experimental, recalcitrância.

\begin{abstract}
This work aims to map the transformations in psychological experiments, specially the change of trained subjects (present in the XIX century laboratories) to the naïve subjects, that after the 1910's decade, became the pattern, in a kind of design, where they don't have any idea of what is going on in the experiment. This transformation will be discussed based upon some concepts of the current "Scientific Studies", from Latour, Stengers and Despret: recalcitrance and docility. If the first as the possibility of new questions arising by the researched beings is already considered very rare in human sciences, the second as the acquiescence before research operations tend to become bigger in the models with the so-called naïve subjects.

Keywords: psychological experiments, experimental subject, recalcitrance.

\section{RESUMEN}

El blanco de este trabajo es hacer um mapa de las transformaciuones e los experimentos psicológicos, destacando los desplazamientos de los sujetos participantes de estos, especialmente em el transito de los sujetos entrenados (onipresentes e los laboratorios psicológicos del siglo XIX) para
\end{abstract}


los sujeitos ingenuos, que a partir de la década de 1910, passan a quedarse como el padrón, en un nuevo tipo de design en que estes não tienem más la posibilidad de conocer lo que está en vías de experimentación. Esta transformación será discutida con base en los conceitos de docilidad y recalcitrancia; si esta, como posibilidad de resistencia y planteamento de nuevas cuestiones por parte de los seres investigados ya es considerada pequeña en las ciencias humanas, la primera, o el asentimento delante las operaciones de la investigación tendría a tornarse más presente en las operaciones con los sujetos tratados como ingenuos.

Palabras-clave: experimentos psicologicos, sujeto experimental, recalcitrancia.

\section{Introdução}

Mesmo com todas as transformações mais recentes nos Cursos de Psicologia brasileiros, proporcionados pelas Novas Diretrizes Curriculares (2004), perseveram algumas suposições sobre a pesquisa no campo: 1) Mesmo com o acolhimento das técnicas ditas qualitativas, os métodos quantitativos são considerados como potencialmente mais "objetivos", 2) Dentre os métodos quantitativos, o modelo dito experimental é o portador de maior confiabilidade, dada a busca de controle das variáveis; 3) Controle de variáveis, que implica especialmente na proteção contra qualquer influência dos pesquisadores sobre os pesquisados quanto às metas, problemas e hipóteses da pesquisa. O que consagra um modo de investigação em que os pesquisados são conduzidos e mantidos em uma posição de ingenuidade com relação aos detalhes da pesquisa. Contudo, esta tomada de posição quanto à relação entre investigadores e investigados não é uma constante nos modos de avaliação dos saberes psicológicos (epistemológicos ou não). Apesar das epistemologias mais tradicionais (como os positivismos clássico e lógico) apoiarem a distância entre investigadores e investigados na produção de conhecimentos é encontrar posições alternativas. Assim, na Teoria Ator-Rede de Bruno Latour e especialmente a Epistemologia Política de Vincianne Despret o conhecimento é tomado como articulação entre diversos atores (humanos e não humanos) e não representações distanciadas e controladas entre observadores e observados. Deste modo é possível mapear toda uma série de transformações nos experimentos psicológicos de um modo totalmente diferente dos textos clássicos de história da psicologia (como Boring, 1950/1979) e dos textos mais tradicionais da epistemologia, destacando especialmente os deslocamentos quanto aos modos de relação entre investigadores e investigados. Pois que se nos laboratórios do século XIX, os observadores deveriam ser treinados para fornecer uma descrição precisa das suas experiências, sendo vedado o acesso aos laboratórios de crianças, "primitivos", 
doentes e deficientes mentais, a partir da década de 1910, começa a ser padronizado um novo tipo de design em que os participantes se veem privados do conhecimento das metas dos experimentos (os ditos "sujeitos ingênuos").

O alvo deste trabalho será discutir com base na Teoria Ator-Rede de Bruno Latour e na Epistemologia Política de Vincianne Despret estas transformações nas investigações em psicologia. Para tal, será feita uma rápida apresentação destas abordagens seguida da descrição de algumas transformações nos experimentos em psicologia. Tais transformações serão consideradas notadamente a partir dos conceitos de docilidade e recalcitrância manejados por estes autores. Segundo estes, se a recalcitrância, ou possibilidade de resistência e colocação de novas questões por parte dos seres pesquisados é considerada menos frequente nas ciências humanas, a docilidade, ou - assentimento perante as operações da pesquisa tenderia a se tornar maior nas operações com os dispositivos produtores de "sujeitos ingênuos". Mesmo que os participantes não se revelem tão ingênuos como suposto, o que este tipo de pesquisa acabaria por conduzir seria a redução da possibilidade de recalcitrância, e uma produção extorsiva de subjetividades por meio dos dispositivos de pesquisa. Ao final será feita uma discussão em prol de uma análise mais plural e menos dualista no recurso a tais conceitos, visando a possibilidade de novos modos de investigação em psicologia.

\section{Teoria Ator-Rede e epistemologia política}

As demarcações entre a Teoria Ator-Rede (TAR) e a Epistemologia Política (EP) são difíceis de delimitar. De fato, Latour por vezes parece estar mais próximo conceitualmente de Despret e Stengers que dos demais autores da TAR, como Callon, Law ou Mol. Esta proximidade se torna patente em um artigo, "How to talk about the body?", onde Latour (2004) enumera 10 pressupostos da EP (ou Teoria S-D) que reforçam sua tese de conhecimento como articulação entre corpos e não representação. Neste último caso, o conhecimento científico se daria através da purificação dos dados, em que ao pesquisador caberia apenas a representação dos objetos a partir de sentenças bem construídas. Para estes autores, o conhecimento, ao contrário, se daria sempre como articulação e co-afetação entre entidades, na produção inesperada de efeitos, e não no salto representacional dado na identidade entre uma sentença ou hipótese prévia e um estado de coisas.

Enquanto articulação, o conhecimento científico não se distingue mais entre má e boa representação, mas entre má e boa articulação. No primeiro caso, temos uma situação em que a articulação é extorquida ou condicionada a uma resposta pontual, conduzindo os seres 
pesquisados a um lugar de "docilidade". No segundo, teríamos uma articulação na qual o testemunho iria além da mera resposta, abrindo-se ao risco de invalidação das questões e proposições do pesquisador e a colocação de novas questões pelos entes pesquisados. Aqui teríamos uma relação de recalcitrância.

Ao contrário do que supõe certos pensadores como Herbert Marcuse, para o qual a possibilidade de negação ou resistência seria marca dos seres humanos, estes autores vão opor a recalcitrância dos seres não-humanos à docilidade e obediência à autoridade científica dos seres humanos, se comportando em geral "como objetos obedientes oferecendo aos investigadores apenas declarações redundantes, confortando então estes investigadores na crença de que eles produzem fatos 'científicos' robustos e imitam a grande solidez das ciências naturais" (Latour, 2004, p. 217). Para este autor ainda (Latour, 1997, p. 301), as ciências humanas só se tornariam realmente ciências não se imitassem a objetividade das ciências naturais, mas sua possibilidade de recalcitrância. Como isto se colocaria na história do sujeito experimental em psicologia?

\section{A psicologia no século XVIII: o fácil testemunho das verdades do espírito}

Uma boa parte dos manuais de história da psicologia sugere o trânsito de um "longo passado" de contribuições filosóficas ilustres (dos antigos até a filosofia iluminista do século XVIII) para a "recente história científica", inaugurada nos trabalhos dos primeiros laboratórios científicos, constituídos no final do século XIX. Contudo, esta concepção presente em manuais clássicos, como o de Boring (1950/1979), é contestada por Vidal (2006), que reconhece uma psicologia positiva no século XVIII. Esta psicologia, proposta como disciplina positiva, se faz presente em trabalhos teologia reformista de base tomista, na escola eclética escocesa, nos ideólogos franceses e no pensamento metafísico de Christian Wolff. Esta disciplina seria reconhecida por meio do suposto acesso a todos sujeitos predispostos à auto-observação, dada a suposição de que o conhecimento do próprio espírito é mais fácil de que dos próprios objetos externos.

Numa das versões mais detalhadas da psicologia deste período, teríamos o trabalho de Christian Wolff, se detendo sobre a definição das faculdades da alma e na determinação da sua relação com o corpo, enquanto substâncias de naturezas distintas. Esta "pura ciência da alma", lançava mão de duas abordagens complementares: a psicologia racionalis (dada na postulação a priori das faculdades da alma) e a empirica (dada na descrição a posteriori da alma pela introspecção). Numa versão de maior disseminaçâo, proliferavam as descrições das experiências de vida, tal como as presentes na Revista 
de Psicologia Experiencial ou de Karl Philipp Moritz. Portanto, não era pedido às testemunhas desse saber nenhuma habilidade especial que não fosse a consideração dos temas pertinentes (faculdades da alma e relação desta com o corpo) e a boa descrição dos movimentos do seu espírito. De mais a mais, nada se impunha como limite na descrição da nossa alma; não havia qualquer suposição, por exemplo, de representações inconscientes ou inaccessíveis à introspecção: a alma é marcada pela sua transparência.

Contudo, no final do século XVIII, esta forma de psicologia passa a ser problematizada por filósofos como Imannuel Kant (1781/1994) ${ }^{2}$, apontando para um novo modelo de conhecimento, no qual a psicologia vai se redefinir. Neste modo de pensamento, proliferam as críticas e os vetos a essas psicologias, e mais especialmente às psicologias racional e empírica de Wolff. A psicologia racional é um dos alvos da Crítica da Razão Pura (1871/1994): o suposto conhecimento racional de uma alma imortal está assentado, na verdade, na experiência do sentido interno fenomenal, que diz respeito ao próprio tempo da consciência (objeto da psicologia empírica). Nada teria a ver, pois, com qualquer abordagem a priori da alma imortal. Esta abordagem seria impossível: o Sujeito Transcendental como condição a priori de todo nosso conhecimento, jamais poderia ser objeto de qualquer conhecimento.

Kant conclui que a psicologia racional, portanto é impossível, e tudo o que venha a se afirmar do saber psicológico é, na verdade, psicologia empírica. Esta, inclusive estaria mais próxima do projeto que norteará o surgimento da psicologia experimental no século XIX, visando estudar as ilusões da experiência imediata. Mas, persiste a pergunta: caberia uma ciência aqui? A resposta de Kant nos Princípios Metafísicos da ciência da natureza (1786/1989, p. 32-33): é que a Psicologia Empírica não seria nem uma ciência impropriamente dita, como a química, a qual ainda não operava com relações matemáticas e, portanto, ainda não seria uma ciência propriamente dita. Basicamente para se provar ciência, a Psicologia teria que:

1) Descobrir o seu elemento de modo similar à química, para com isto efetuar análises e sínteses;

2) Facultar a este elemento um estudo de tal modo objetivo, em que sujeito e objeto não se misturem como na introspecção;

3) Que se produza uma matematização mais avançada que geometria da linha reta, apta a dar conta das sucessões temporais do sentido interno.

\section{A psicologia do século XIX e a encarnação fisiológico- sensorial}


Esta crítica, assim como a estabelecida por outros filósofos como Comte (1851/1973) não excluíram imediatamente os modos de testemunho presentes na psicologia do século XVIII. Contudo as transformações nos modos de testemunho da psicologia serão tomadas das mudanças operadas na fisiologia do século XIX. Elas, indiretamente ofereciam subsídios para a contraposição de vetos como os kantianos. Assim um candidato à unidade de análise fiável poderia ser buscado nas sensações, tal como estabelecido na teoria das energias nervosas específicas de Johannes Muller. I gualmente a busca de formalização matemática pôde conduzir ao acolhimento da Lei psicofísica de Gustav Fechner, na correlação entre sensações e estímulos. Mas a busca de um modo mais "objetivo" e distanciado na relação entre observador e observado conduziu ao acolhimento da introspecção experimental de Ludwig Von Helmholtz.

Helmholtz elaborou em 1860 uma teoria (a das inferências inconscientes) sobre o surgimento das representações psicológicas acoplado a um método para estudo objetivo das sensações de base (o da introspecção experimental). Segundo a teoria das inferências inconscientes, as nossas sensações seriam organizadas por experiências passadas, que atuariam ao modo de premissas lógicas, como as de um silogismo. De modo mais específico, as experiências passadas ordenariam de modo inconsciente e rápido as informações trazidas pelos sentidos, produzindo como conclusão as nossas representações psicológicas. O modo de análise das sensações, a introspecção experimental, se processaria no inverso dessas sínteses inconscientes, visando neutralizar os efeitos dessa inferência lógica operada pela experiência passada. Para neutralizar esta síntese inconsciente, processa-se então uma análise consciente, em que os observadores dos experimentos são treinados para reconhecer 0 aspecto sensorial mais bruto e selvagem de nossa experiência. Este treinamento dos participantes, que faz com que este estudo não possa ser feito sobre crianças, primitivos, ou doentes mentais, visa o evitar o erro do estímulo, qual seja, a confusão do objeto percebido com os juízos inconscientes acumulados pela experiência passada. Por isto, o estudo objetivo das sensações em um sujeito só poderia ser feito se este mesmo sujeito for também um fisiólogo, apto a distinguir o joio da experiência passada do trigo das sensações. Ainda que mantendo aos observados um papel ativo na investigação, há uma enorme distância da introspecção praticada na psicologia do século XVIII.

Este modo de experimentação fisiológica foi constitutivo de uma psicologia devotada agora ao entendimento da experiência comum (ou imediata) a ser distinta da experiência física (ou mediata). Impõe-se assim o problema do conhecimento, na busca de se demarcar a diferença entre uma experiência passível de 
representação correta dos fenômenos pelo uso de mediadores como conceitos e instrumentos (a física) em contraste com outra notadamente falseadora (a psicológica), que operaria sem qualquer mediação. Na requisição de um corpo epistemológico, a psicologia teve que disponibilizar de um corpo fisiológico, com seus modos de produção de testemunho. Para tal, a experiência imediata, recheada de sensações, deveria ser estudada por uma forma de experiência mediata, a introspecção experimental, na qual os sujeitos devidamente treinados - deveriam decantar da totalidade da experiência os seus aspectos sensoriais.

Neste modelo de investigação, como nos lembra Despret (2004, p. 62 ), as funções de experimentador e de sujeito eram perfeitamente intercambiáveis. Inclusive este último tinha uma designação completamente distinta: era chamado de observador, por vezes recebendo uma designação ainda mais específica, conforme a função realizada: reator, discriminador, etc. (op. cit., p. 63) ${ }^{3}$. De mais a mais o papel do observador era avaliado como mais complexo que o de experimentador, supondo até mesmo um maior desgaste seu: Wilhelm Wundt (considerado o fundador institucional desta psicologia) a maior parte de seus experimentos teria feito o papel de observador. É digno de nota que os observadores inclusive assinavam como autores principais os trabalhos publicados (op. cit., p. 64). Em poucas palavras, a formação do observador "se constituía como uma técnica de si sobre si, como uma expertise na formação de si: a vontade, a atenção, o controle do corpo, a clivagem da consciência" (op. cit., p. 96). Praticamente uma verdadeira "técnica de si" de cunho experimental, no sentido que Foucault (1996) postula.

\section{Ascensão e declínio do sujeito expert: a psicologia animal, o gestaltismo e o behaviorismo}

Este modo de produção de testemunhos psicológicos sofre na seqüência modos de problematização bem distintos, mas que conduzem a uma redefinição dos testemunhos psicológicos. Despret (2004) analisa esta passagem em um dispositivo bastante específico: aquele desenvolvido pelo psicólogo austríaco Oskar Pfungst na primeira década do século XX para estudar o cavalo Hans, que possuía a excepcional capacidade de responder com batidas de suas patas a operações matemáticas. A fim de evitar hipóteses relativas a estados paranormais e de recusar qualquer atribuição de uma capacidade cognitiva superior ao animal, Pfungst explora a possibilidade de que a solução de problemas poderia se dever a algum sinal inconscientemente enviado pelo proponente das questões ao cavalo. $\mathrm{Na}$ busca deste possível sinal, Pfungst introduz inicialmente no dispositivo um participante que desconhece a questão 
ou o que foi proposto. Observando os erros nas respostas do cavalo neste caso, o psicólogo alemão parte para a pesquisa do possível sinal emitido pelos presentes, encobrindo sistematicamente partes de seus corpos. Após algumas variações, Pfungst detecta que próximo da resposta esperada os participantes realizariam um sutil deslocamento postural na ordem de milímetros. Levando esta idéia adiante, o psicólogo austríaco inclusive simula o papel do cavalo, convocando aos participantes (que desconhecem sua hipótese) pensem em um número no qual ele adivinharia, o que realiza frequentemente. Ainda que este psicólogo alemão realizasse vários exercícios introspectivos (como era próprio do treinamento dos psicólogos na época), ele é um dos primeiros a introduzir nos laboratórios de psicologia, sujeitos que desconhecem o artefato em questão.

Contudo, a esta entrada sub-reptícia do sujeito ingênuo nos laboratórios de psicologia se radicaliza na década de 1910 por meio da crítica ao próprio observador treinado como entrave às pesquisas ditas "objetivas". Este observador ativo, que tinha sido o personagem fiador da objetividade dos experimentos psicológicos, torna-se o seu próprio obstáculo. Para isto é de suma importância reportar as críticas produzidas por duas orientações psicológicas que surgem neste período tanto na Alemanha quanto nos Estados Unidos e que vão pouco a pouco se tornando predominantes no campo. Tratam-se das tendências behaviorista e a gestaltista (da Escola de Berlim), mesmo que estas tenham orientações opostas em seus projetos.

A modificação conduzida pelo gestaltismo principia-se pela radicalização do projeto de psicologia anterior pelo seu próprio alvo: a experiência. Metodologicamente há um questionamento da própria introspecção experimental, mostrando-se a artificialidade deste procedimento: o treinamento dos observadores, a busca das sensações puras e o risco do erro do estímulo são considerados pelos gestaltistas como mero preconceito fisiológico, configurando este em um erro crucial: o "erro da experiência" (Köhler, 1947/1968). O gestaltismo propõe em contrapartida uma estratégia supostamente mais conforme a experiência tomada em sentido amplo: o método fenomênico, proposto por Carl Stumpf ${ }^{4}$. Aqui o controle não é mais feito sobre o próprio sujeito experimentado, mas sobre as condições experimentais que são apresentadas aos participantes dos experimentos. Destes se espera que a sua descrição e reação sejam as mais puras e diretas, seja a de um adulto / de uma criança; de um indivíduo normal / suposto portador de patologia; civilizado / supostamente primitivo; homem / animal. Aqui a psicologia sairia da exclusividade do estudo dos indivíduos adultos, normais, civilizados e treinados, como era próprio da psicologia anterior. Entra em cena um certo sujeito ingênuo como protagonista nos laboratórios 
psicológicos. O controle do experimento agora passa a pertencer ao experimentador.

Contudo, mesmo que na posição de "sujeitos ingênuos", aqueles que participam dos experimentos têm uma relevância especial na descrição desta experiência, tal como esta se daria em um sentido global. O Gestaltismo considera a descrição dos experimentados extremamente preciosa (mesmo desconhecendo as metas dos experimentos), operando-se aqui posição de um quase-expert em sua ingenuidade. Outro aspecto crucial dos experimentos gestaltistas é a gama de opções favorecidas aos experimentados. Assim, por exemplo, nos experimentos de Köhler (1971) com chimpanzés, era oferecida uma ampla gama de alternativas para solução de problemas, permitindo que os animais pudessem produzir novos testemunhos surpreendentes inovadores.

Contudo, a expressão mais radical do dispositivo do sujeito ingênuo foi fornecida pelo behaviorismo norte-americano. Este, ao contrário do gestaltismo, não pretende uma reforma do projeto de uma "ciência da experiência". Na verdade ele se constitui de forma radicalmente oposto ao gestaltismo, na crítica à inadequação da experiência como objeto de uma psicologia que se deseje cientificamente respeitável. Entende que este projeto científico só possui sentido com o descarte da consciência e da mente do universo da psicologia. Sendo igualmente inaccessível a observação e controle público, estas entidades serão recusadas e posteriormente negadas em sua existência. Em seu lugar permanece uma série de mecanismos de regulação da conduta observados na conduta animal, sejam os condicionamentos-reflexos (propostos por Ivan Pavlov), sejam os condicionamentos-operantes (postulados por Edward Thorndike em sua lei do Efeito). Tudo isto para facultar uma psicologia mais objetiva e eficaz em seus controles da conduta (este o derradeiro critério de cientificidade). Em que, aos sujeitos estudados (agora entendidos como meros organismos), nada mais restaria a fazer senão reagir aos dispositivos postulados. Não se trata apenas do apogeu do dispositivo do sujeito ingênuo, mas do sujeito meramente reativo às forças do ambiente, controladas inteiramente pelos pesquisadores.

\section{Sujeito ingênuo, docilidade e recalcitrância}

A ascensão do dispositivo sujeito ingênuo parece, a princípio o trunfo de uma psicologia mais objetiva e sem qualquer influência prévia do pesquisador ou de um referencial teórico sobre as reações autênticas de seus testemunhos. Contudo, esta leitura é revertida tanto pela Teoria Ator-Rede quanto pela Epistemologia Política, que tomam o conhecimento como articulação, que pode ser de extorsão \& 
docilidade ou recalcitrância. Como isto se colocaria na história do sujeito experimental em psicologia? Para Despret (2004) a possibilidade da recalcitrância jamais se colocaria do lado de qualquer dispositivo favorecedor do "sujeito ingênuo", daquele que pode ser qualquer um; esta se colocaria ao lado apenas dos dispositivos produtores de "sujeito expert", daquele que é capaz de recolocar questões. Aqui teríamos uma reversão com relação à maior parte dos manuais de história da psicologia: a passagem do sujeito treinado para o sujeito ingênuo não representa um passo adiante do conhecimento psicológico na direção da objetividade e do controle, mas um passo atrás na possibilidade de recalcitrância, engendrando articulações dóceis, assimétricas e limitadoras com relação aos seus testemunhos. Participantes sem a excelência da expertise não trazem risco de tomar posição nas investigações (op. cit., p. 97). É neste pacto que se fundariam os atuais laboratórios psicológicos.

Contudo, este dispositivo não garantiria uma posição de derradeira ingenuidade por parte dos testemunhos psicológicos: apenas uma posição ambivalente destes, entre a confiança, dada no crédito aos cientistas, e a desconfiança de que algo se esconde. Para tal, Despret (op. cit., p. 99) destaca como exemplar deste quadro, um dos experimentos mais emblemáticos na produção de "sujeitos ingênuos": o relativo à obediência a autoridade realizado por Stanley Milgram (1974). Apenas recordando, nesta investigação os participantes convidados a participar são lançados em uma situação em que tudo se assemelha a um experimento comum sobre aprendizagem e memória: os dólares pagos pela participação, uma sala na prestigiosa universidade de Yale, um outro participante a ser testado e a presença do cientista afiançando as operações ali existentes: a tarefa de dar uma carga elétrica no participante a ser testado a cada erro, aumentando esta conforme o número de erros. A constituição do dispositivo constituinte de um sujeito ingênuo se dá não apenas nos diversos engodos do experimento (a inexistência de qualquer carga elétrica e a identidade do outro participante como um ator que simula problemas cardíacos a cada suposta carga), mas na ocultação dos objetivos: a busca de saber até onde os participantes seguiriam na obediência à autoridade do cientista. Os resultados iniciais apontaram que $65 \%$ de tais "sujeitos ingênuos" sob o estímulo do cientista chegam até a administração da carga limite de 450 volts (mesmo com muitas hesitações).

Como os participantes tornados ingênuos tomaram o experimento e a própria ingenuidade a que foram submetidos? Aqui deve se destacar dois aspectos relacionados às entrevistas feitas a posteriori aos participantes: 1) $84 \%$ sustentaram que estavam "contentes" ou "muito contentes" de haver participado do experimento e $15 \%$ que Ihes era indiferente; 2 ) muitos observaram que havia algo estranho no experimento, especialmente dado que um cientista de Yale não 
poderia de fato sustentar tais práticas. Mas, como era um cientista de Yale, valia seguir até o fim. Para Despret estes relatos apontam para uma espécie de clivagem na consciência, típica das situações de confiança \& desconfiança conjuntas: a obediência ao cientista, mas com "uma pulga atrás da orelha", na tentativa de se entender o que se passa. Para a autora, este "desconhecimento" imposto ao sujeito ingênuo seria também visto como inútil e empobrecedor, pois não apenas não exclui a complacência, como se evitam outras possibilidades de intercâmbio entre investigadores e investigados (op. cit., p.100). Concluindo sua abordagem, Despret (2004, p. 102) enuncia a alternativa para os dispositivos psicológicos: estes poderiam ser "o lugar de exploração e de criação disso que os humanos podem ser capazes quando se os trata com a confiança que se dispensa aos experts".

\section{Conclusão}

A discussão proposta por Latour e especialmente por Despret sobre as pesquisas em psicologia são cruciais, não apenas na resignificação do que se busca como sentido científico destas (quanto à docilidade e recalcitrância), mas, principalmente, na redescrição histórica destes dispositivos (notadamente dada a ascensão do "sujeito ingênuo"). Assim, se tradicionalmente esta passagem é vista como a ascensão na direção de uma psicologia mais objetiva e mais isenta de qualquer influência e cumplicidade entre pesquisadores e pesquisados, Despret verá aí o trunfo dos modos docilizantes de articulação.

Tais ganhos nesta rediscrição, contudo podem avançar por meio de outras questões a serem adicionadas: 1) Seria a posição de expert o único requisito para uma pesquisa marcada pela recalcitrância? 2) Haveria uma total coincidência entre as posições expert / ingênuo e entre recalcitrância e docilidade? 3) Não haveria a possibilidade de uma tipologia menos dualista com outros casos intermediários?

Sobre a primeira questão, é necessário se destacar que a posição de expert pode não ser um critério isolado para a recalcitrância. Esta suspeita vem primeiro devido aos resultados atuais de uma investigação sobre os modos de subjetivação psicologizados junto a estudantes de segundo-grau no Rio de Janeiro (Ferreira et al, 2011): a distinção entre grupos submetidos a dispositivos "expert" (com conhecimento dos objetivos da pesquisa) e "ingênuos" (sem conhecimento dos objetivos da pesquisa) não produziu resultados muito distintos. Igualmente isto ocorre em pesquisa que estamos realizando junto a usuários de terapias psi (psicanalítica, cognitivacomportamental, gestaltista e esquizo-analítica) de uma Divisão de Psicologia Aplicada da UFRJ, o convite a uma posição expert nas entrevistas não implica em uma necessária saída de uma postura 
dócil. Mesmo com todos os esforços para se co-dividir o papel de expert, os pesquisados podem ainda se ver diante de um forte componente de "autoridade" no psicólogo-pesquisador, que pode conduzi-los a uma situação de suposto "teste de conhecimentos psi" sobre suas próprias experiências. Como se coubesse sempre sobre 0 psicólogo saber mais sobre os pesquisados, oferecendo estes em geral respostas muito canônicas (nada muito distintas dos manuais tradicionais) sobre as psicologias e os processos terapêuticos ${ }^{5}$.

Sobre a segunda e terceira questões, os experimentos gestaltistas com animais e "sujeitos ingênuos" apontam para a necessidade de se abrir um leque mais amplo e sutil nas graduações entre as posições expert e ingênuos. Pois, se por um lado há a constituição de um dispositivo em que o pesquisado não conhece mais os meandros da pesquisa, por outro há uma total confiança em seu testemunho, caracterizando-se estes como "quase-experts", ou "expertsingênuos". Mesmo na pesquisa com os animais (especialmente comparadas com as behavioristas das caixas de Thorndike e Skinner), abrem-se muito mais possibilidades de testemunhos inovadores. De modo que, junto ao convite a uma posição de expert, é necessária também a postulação de um dispositivo que se submeta ao risco (Latour, 2004), abrindo a possibilidade de testemunhos inovadores. E isso não se pode negar à escola gestaltista de Berlim, ainda que tais testemunhos sejam vinculados às leis da Forma de caráter universal e onipresentes em todos os domínios da natureza (psicológico, fisiológico e físico).

Tais ponderações às distinções propostas por Latour e especialmente por Despret são fundamentais para a abertura de novos modos de se fazer psicologia. Certamente não mais uma psicologia que buscaria o testemunho monocórdio de uma lei universal nas reações dos "sujeitos a condições limitadoras", mas outras formas em que se ensaiam novas e mais novas versões nos modos em que podemos nos produzir ao mesmo ato que nos conhecemos. Sem qualquer princípio naturalizador que arbitre sobre os assuntos cotidianos e os fundamentos transcendentais da nossa existência. Pois estes princípios não se definem a priori, mas somente na articulação diferencial e múltipla das nossas versões psi e por meio de dispositivos bem concretos. A serem agora considerados e costurados em um processo maior de produção de um "pluriverso" de subjetivações.

\section{Referências}

Araujo, S. (2012). The question of Empirical Psychology in the Precritical period: a case of discontinuiy in Kant's thought. In: Bacin, S., Ferrarin, A., La Rocca, C., Ruffing, M. (Orgs.) 
Proceedings of the XI International Kant Congress (pp. 359366) Berlin: Der Gruyter.

Boring, E. G. (1979). Historia de la Psicología Experimental (R. Ardilla, Trad.) México: Trillas (original publicado en 1950).

Comte, A. (1973) Curso de filosofia positiva. In J. A. M., Pessanha (Org.). Os Pensadores. (pp. 9-45). (J. A. Giannotti, Trad.). São Paulo: Abril (original publicado em 1837).

Curvelo, F. (2014). A Gestalttheorie e a Fenomenologia de Edmund Husserl: uma investigação de seus antecedentes intelectuais comuns e de suas relações metodológicas e conceituais. Dissertação de Mestrado, Universidade Federal do Rio de J aneiro, Rio de Janeiro, RJ , Brasil.

Despret, V. (2004). Le cheval qui savait compter. Paris: Les empecheurs de penser en ronde.

Ferreira, A. L. F., Pereira, C. S., Hauttequest, F., Gomes. G.A., Brandão, J. T., Pereira, N. B., \& Madeira, R. J. P. (2011). A psicologia como um dispositivo de produção de subjetividades: um percurso pelos métodos quantitativos. Revista investigação e práticas psicossociais, 6(2), 222-233.

Foucault, M. (1996). Tecnologías del yo. In M. Morey (Org). Tecnologías del yo, (pp. 45-94). (Mercedes Allendesalazar, Trad.). Barcelona: Paidós/ICE - UAB.

Kant, I. (1994). Crítica da Razão Pura (M. P. dos Santos, \& A. F. Morujão, Trad.) Lisboa: Calouste Gulbekian (original publicado en 1781).

Kant, I. (1989). Principios metafísicos de la ciencia de la naturaleza (C. Másmela, Trad.). Madrid: Alianza (original publicado en 1786).

Köhler, W. (1968). Psicologia da Gestalt (Trad. D. Jardim). Belo Horizonte: Itatiaia (original publicado em 1947).

Köhler, W. (1971). A compreensão dos macacos superiores. In E. G. Boring, \& R. J. Herrnstein (ORGS.). Textos básicos de historia da psicologia (pp.704-714). (D. M. Leite, Trad.). São Paulo: Herder / Edusp (original publicado en 1917).

Latour, B. (1997). Des sujets recalcitrants. In: Recherche, Setembro de $1997,301$.

Latour, B. (2004). How to talk about the body. Body \& Society, 10(23), 205-229.

Milgram, S. (1974). Obedience to Authority: An Experimental View. New York: Harper and Row.

Novas Diretrizes Curriculares (2004) Resolução CNE/CES № 8, de 7 de maio de 2004. Recuperado em 28 de fevereiro de 2012, de http: //portal.mec.gov.br/index.php?option=com_content\&view $=$ article\&id $=12991$

Vidal, F. (2006). A mais útil de todas as ciências. Configurações da psicologia desde 0 Renascimento tardio até 0 fim do 
Iluminismo. In A. A. L. Ferreira, \& F. T. Portugal (Orgs.). História da psicologia: rumos e percursos (pp. 47 -73). Rio de Janeiro: Nau.

\section{Endereço para correspondência Arthur Arruda Leal Ferreira}

Universidade Federal do Rio de J aneiro

Instituto de Psicologia, Departamento de Psicologia Geral e Experimental

Avenida Pasteur, 250, Pavilhão Nílton Campos, Praia Vermelha, CEP 22290-240, Rio de Janeiro - RJ, Brasil

Endereço eletrônico: arleal@superig.com.br

Recebido em: 04/06/2014

Aprovado em: 04/06/2014

\section{Notas}

* Professor associado do Instituto de Psicologia da UFRJ (Rio de Janeiro/Brasil), bolsista de produtividade (CNPq) e doutor em Psicologia Clínica pela PUC/SP

${ }^{1}$ Este texto é uma tradução adaptada e atualizada do artigo "Jamás hemos sido ingenuos (dóciles sí, pero ingenuos jamás): un estudio sobre la constitución del sujeto ingenuo en los laboratorios psicológicos" publicado na coletânea "Teoría del Actor-Red: Más allá de lós estúdios de Ciencia Y tecnología" organizada por Daniel Lopez e Francisco Tirado e publicado em 2012 pela editora Amentia de Barcelona. Agradeço à professora Marcia Moraes da UFF pela leitura atenta do artigo e as observações especialmente relativas ao gestaltismo da Escola de Berlim

${ }^{2}$ Segundo Araújo (2012), a relação de Kant com a psicologia é mais complexa que a simples postulação de críticas, envolvendo a proposição de uma psicologia empírica com algumas variantes em seu trabalho

${ }^{3}$ Segundo Despret (2004: 63), o uso do termo sujeito não é sem importância; ele traduziria uma assimetria quanto à especialização e aos papéis desempenhados entre experimentador e experimentado. Ele viria da tradição da psicologia experimental francesa (importado do campo da cirurgia médica), refletindo um tipo de pesquisa realizado em torno da hipnose, contando com a total passividade do experimentado

4 Conferir a dissertação de Flávio Vieira Curvelo: A Gestalttheorie e a Fenomenologia de Edmund Husserl: uma investigação de seus antecedentes intelectuais comuns e de suas relações metodológicas e conceituais (Curvelo, 2014). Aqui é claramente colocada a vinculação do conceito de fenomenologia do Gestaltismo com a proposta de Stumpf, de resto, bem distinta da de Husserl

${ }^{5}$ Mas por vezes entre os entrevistados pode se destacar uma posição mais de expert na forma com que estes se apropriam dos dispositivos psicológicos, produzindo diários e estratégias de auto-observação, ao modo das técnicas de si destacadas por Foucault (1996) 